\title{
Transient Stability Enhancement of Wind Generator by PWM Voltage Source Converter and Chopper Controlled SMES Unit
}

\author{
M. R. I. Sheikh and A. B. M. Nasiruzzaman ${ }^{1}$ \\ EEE Department, Rajshahi University of Engineering \& Technology, Rajshahi-6204, Bangladesh
}

Received 10 November 2008, accepted in final revised form 7 February 2009

\begin{abstract}
In order to investigate the impacts of the integration of wind farms into utility networks, transient stability should be analyzed before connecting wind turbine generator system (WTGS) to the power system. This paper proposes a robust controller for superconducting magnetic energy storage (SMES) unit to enhance the transient stability of a grid connected fixed speed wind generator system. In the proposed controller, both SMES active and reactive powers are controlled to decrease the fluctuations of output power and terminal voltage of the wind generator during transient condition. The power conversion system (PCS) of SMES unit used in this paper is composed of a sinusoidal pulse width modulated voltage source converter (PWM-VSC) and a two-quadrant DC-DC chopper using Insulated Gate turn-off Bipolar Transistors (IGBT). Stability during symmetrical and unsymmetrical faults in the network system is analyzed. The effects of the faults on the generator dynamics are also discussed clearly. Simulation results demonstrate that the proposed SMES controller is very effective for stabilizing wind generator as well as the entire power system.
\end{abstract}

Keywords: Fixed speed wind generator system; Transient analysis; System faults; PWMVSC; DC-DC chopper and SMES unit.

(C) 2009 JSR Publications. ISSN: 2070-0237 (Print); 2070-0245 (Online). All rights reserved.

DOI: $10.3329 /$ jsr.v1i2.2281

\section{Introduction}

Recently, shortages of fossil fuel and environmental global warming have become serious problems. It is thus necessary to introduce clean energy more in place of the fossil fuel. As wind power is one of the prospective clean energy resources, a large number of wind farms are being in service in the world. The wind power is increasingly considered not only a means to reduce the $\mathrm{CO}_{2} / \mathrm{NOx} / \mathrm{SO}_{2}$ emissions generated by traditional fossil fuel-fired utilities, but also a promising economic alternative in areas with appropriate wind conditions. Wind power is expected to play a comparatively significant role in future national energy scene. As penetration levels of wind power increases, the assessment of the effects of the wind power penetration on existing interconnected large-scale power systems becomes very important and imperative. Stability analysis of doubly fed induction generator (DFIG) type variable speed wind turbine (VSWT) and permanent

\footnotetext{
${ }^{1}$ Corresponding author: nasir_zaman_eee@yahoo.com
} 
magnet synchronous generator (PMSG) is already reported in many literatures [1-3]. On the other hand, although the stability analysis of synchronous generator has been done extensively in many literatures [4-5], it is insufficient when fixed speed induction machine is used for wind power generation with full rating of power converter topology. The fixed speed wind turbine connected with an induction generator (squirrel cage or wound rotor) is widely used because of its advantages of being simple, robust, reliable, and well proven. It can supply power directly to the electric grid. Also, the cost of its electrical parts is low. In 2004, the worldwide market share of fixed-speed wind generator was around $40 \%$ [6]. In some countries such as Japan, the fixed-speed wind generator is around 70\% [7].

A lot of research has been performed for smoothing output power generated from fixed speed wind generators. Usually, stabilization of wind generator is done by static VAR compensator (SVC) [8] or static compensator (STATCOM) [9]. However, SVC or STATCOM can control only reactive power. A flywheel energy storage system is proposed [10] to smooth the wind power fluctuations. On the other hand an energy capacitor system (ECS) consisting of power electronic devices and electric double layer capacitor (EDLC) is proposed [11] to smooth wind farm output. But a flywheel system has, in general, high standby loss within the range of $5 \%$ of its power rating. Moreover, the control scheme of flywheel system is comparatively complex. Though BES [12] and ECS [7] are good systems for the power smoothing due to their high response speed and high efficiency, their practical installation in large MW range applications is difficult due to their high maintenance cost. Also it has some drawbacks such as shorter life cycle and low discharge rate due to chemical reaction rates.

On the other hand, though SMES has high initial installation cost, intensive progress in power electronics and superconductivity has provided power transmission and distribution industry with SMES units. Since the successful commissioning test of the BPA $30 \mathrm{MJ}$ unit [13], SMES systems have received much attention in power system applications, such as, diurnal load demand leveling, frequency control, automatic generation control, uninterruptible power supplies, etc. $[14,15]$. SMES is a large superconducting coil capable of storing electric energy in the magnetic field generated by DC current flowing through it. Depending on the control loop of its power conversion unit and switching characteristics, the SMES system can respond very rapidly [16, 17]. The SMES system is combined with the voltage source IGBT converter is capable of effectively controlling and near instantaneously injecting both active and reactive power into the power system and thus enhance system reliability and availability.

In this work a PWM voltage source converter and a two-quadrant DC-DC chopper using insulated-gate-bipolar-transistor (IGBT) is used for SMES control. Therefore, the SMES can be operated to provide independent control of real and reactive power. Charge and discharge of SMES are determined by the chopper duty cycle. A SMES unit based on a self-commutated inverter using IGBT is capable of controlling both the active and reactive powers simultaneously and quickly. Therefore, it can act as a good tool to decrease voltage and power fluctuations of the system considerably. Considering these 
viewpoints, the proposed control strategy is a very effective means for enhancing transient stability of wind generator and also a good tool for entire power system.

\section{Model System}

Fig. 1 shows the model system where one synchronous generator (SG) is connected to infinite bus through a transformer and a double circuit transmission lines. The line parameters are numerically shown in the form of $R+j X$. One induction generator (IG) is connected with the network via a transformer and a short transmission line. Though a wind power station is composed of many generators practically, it is considered to be composed of single generator with the total capacity in this paper. A capacitor bank $C$ has been used at the wind generator terminal for reactive power compensation at steady state. The automatic voltage regulator (AVR) and Governor control system models are same as those used in [18]. Generator parameters are shown in Table 1. The system base power is 100 MVA. As induction machine is widely used as wind generator, we need to be careful about one of its properties such as reactive power compensation. To establish the rotating magnetic field of the stator, reactive power is needed to be supplied from the network to the stator winding of the induction generator. To compensate the reactive power demand at steady state, a capacitor bank is inserted at the terminal of IG [19, 20]. The value of the capacitor $C$ is so chosen that the power factor of the wind power station becomes unity when it is operating in the rated condition $(V=1.0, P=0.5)$. As a result, during load flow calculation this reactive power, $Q_{C}$, supplied by the capacitor bank should be considered.

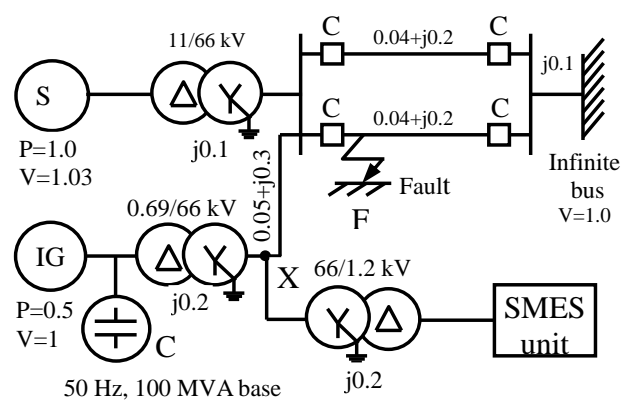

Fig. 1. Power system model.

\section{Wind Turbine Modeling}

\subsection{Model system analysis}

The model of wind turbine rotor is complicated. According to the blade element theory [21], modeling of blade and shaft needs complicated and lengthy computations. Moreover, it also needs detailed and accurate information about rotor geometry. For that reason, considering only the electrical behavior of the system, a simplified method of modeling of the wind turbine blade and shaft is normally used. The mathematical relation for the mechanical power extraction from the wind can be expressed as follows [21]: 


$$
P_{w}=0.5 \rho \pi R^{2} V_{w}^{3} C p(\beta, \lambda),
$$

where $P_{w}$, is the extracted power from the wind, $\rho$ is the air density $\left[\mathrm{kg} / \mathrm{m}^{3}\right], R$ is the blade radius $[\mathrm{m}]$ and $C_{p}$ is the power coefficient which is a function of both tip speed ratio, $\lambda$, and blade pitch angle, $\beta$ [deg]. $\lambda$ and $C_{p}$ are expressed as [22]:

$$
\begin{aligned}
& \lambda=\frac{V_{w}}{\omega_{B}}, \\
& C_{p}=\frac{1}{2}\left(\lambda-0.022 \beta^{2}-5.6\right) e^{-0.17 \lambda,}
\end{aligned}
$$

where, $\omega_{B}$ is the rotational speed of turbine hub [rad/s]. Here wind speed, $V_{w}$, is in mile/hr. The $C_{p}-\lambda$ curves are shown in Fig. 2 for different values of $\beta$. Power versus wind speed characteristic is also shown in Fig. 3 . When the wind velocity exceeds the rated speed, then the pitch angle of the blade needs to be controlled to maintain the output at the rated level. Fig. 3 shows the control of pitch angle with the variation of wind velocity to control the output power nearly constant at rated capacity. Now the turbine torque, $T_{w}$, can be calculated from Eq. (4):

$$
T_{w}=0.5 \rho \pi R^{2} V_{w}^{2} C p(\beta, \lambda) / \lambda,
$$

Table 1. Generator parameters.

\begin{tabular}{llll}
\hline \multicolumn{3}{c}{ SG } & \multicolumn{2}{c}{ IG } \\
\hline MVA & 100 & MVA & 50 \\
$\mathrm{Ra}(\mathrm{pu})$ & 0.003 & $\mathrm{r} 1(\mathrm{pu})$ & 0.01 \\
$\mathrm{Xa}(\mathrm{pu})$ & 0.13 & $\mathrm{x} 1(\mathrm{pu})$ & 0.1 \\
$\mathrm{Xd}(\mathrm{pu})$ & 1.2 & $\mathrm{Xmu}(\mathrm{pu})$ & 3.5 \\
$\mathrm{Xq}(\mathrm{pu})$ & 0.7 & $\mathrm{r} 21(\mathrm{pu})$ & 0.035 \\
$\mathrm{Xd}(\mathrm{pu})$ & 0.3 & $\mathrm{x} 21(\mathrm{pu})$ & 0.030 \\
$\mathrm{Xq}(\mathrm{pu})$ & 0.22 & $\mathrm{r} 22(\mathrm{pu})$ & 0.014 \\
$\mathrm{Xd}{ }^{\prime \prime}(\mathrm{pu})$ & 0.22 & $\mathrm{x} 22(\mathrm{pu})$ & 0.098 \\
$\mathrm{Xq}{ }^{\prime \prime}(\mathrm{pu})$ & 0.25 & $\mathrm{H}(\mathrm{sec})$ & 1.5 \\
$\mathrm{Td} 0^{\prime}(\mathrm{sec})$ & 5.0 & & \\
$\mathrm{Td} 0^{\prime \prime}(\mathrm{sec})$ & 0.04 & & \\
$\mathrm{Tq} 0^{\prime \prime}(\mathrm{sec})$ & 0.05 & & \\
$\mathrm{H}(\mathrm{sec})$ & 2.5 & & \\
\hline
\end{tabular}

\subsection{Pitch controller}

The conventional type of pitch controller is used in the simulations, which controls the wind generator output power at rated level when wind speed is over the rated speed. The block diagram of the pitch controller is shown in Fig. 4. The pitch servo is modeled with a first order delay system with a time constant $T_{d}=5 \mathrm{sec}$. Because the pitch actuation system cannot, in general, respond instantly, a rate limiter with a value of $10^{\circ} / \mathrm{sec}$ is added. PI controller is used in the control system block. The values of proportional gain and integral time constant are chosen 50 and 0.3 , respectively. 

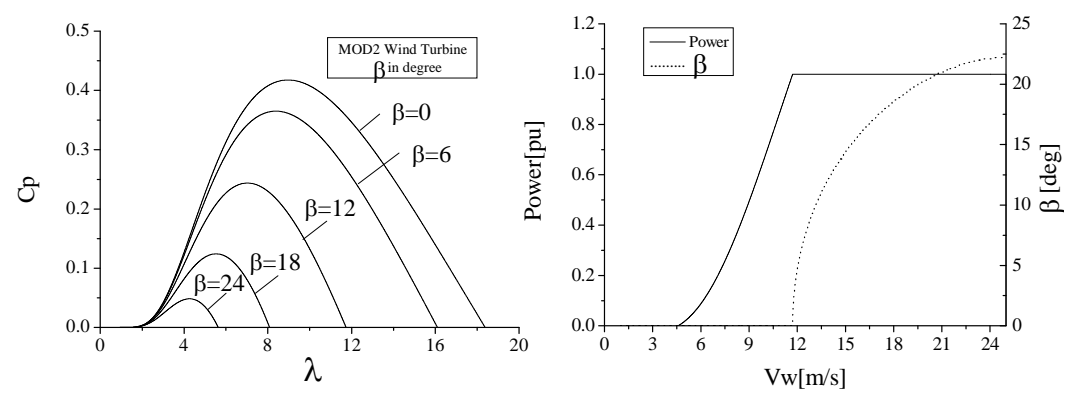

Fig. 2. $C_{P^{-}} \lambda$ curves for different pitch angles. Fig. 3. Power vs. $V_{w}$ and pitch angle $(\beta)$ vs. $V_{w}$ characteristics.

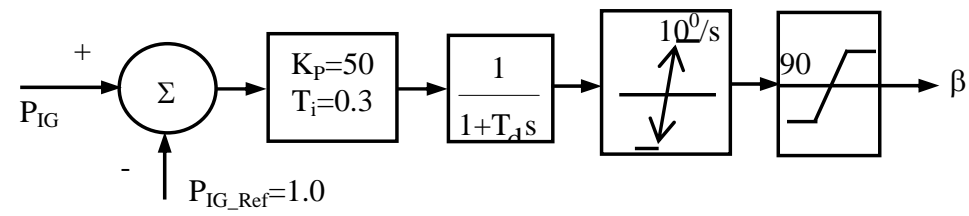

Fig. 4. Pitch angle controller.

\section{Control System of SMES}

\subsection{Brief overview of SMES system}

The SMES unit model used in this paper is shown in fig. 5. It consists of a Wye-Delta transformer, a 6-pulse PWM-VSC using IGBT, a DC link capacitor, a two-quadrant DCDC chopper using IGBT, and a superconducting coil or inductor of $0.5 \mathrm{H}$. The VSC and the DC-DC chopper are linked by a DC link capacitor of $50 \mathrm{mF}$. The SMES unit here has the rating of $50 \mathrm{MW}, 0.05 \mathrm{MWH}$.

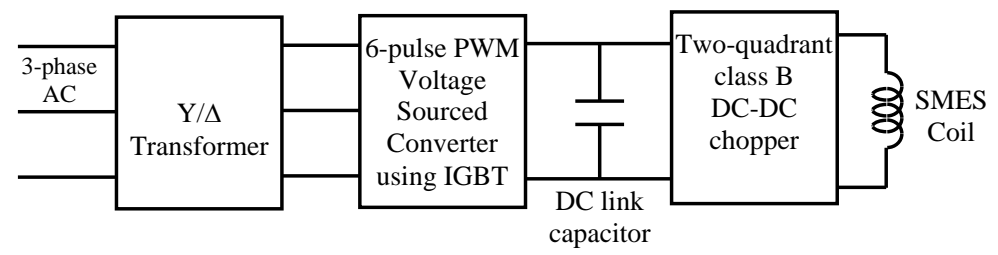

Fig. 5. Basic components of the SMES. Unit.

\subsection{PWM voltage source converter}

The PWM voltage source converter provides a power electronic interface between AC power system and the superconducting coil. DC link voltage $V_{d c}$ and grid point voltage $V_{G}$ are maintained constant by the VSC. The control system of the VSC is shown in Fig. 6. The PI controllers determine reference $d$ - and q-axis currents by using the difference between the DC link voltage $V_{d c}$ and reference value $V_{d c-r e f}$, and the difference between 
terminal voltage $\mathrm{V}_{\mathrm{G}}$ and reference value $\mathrm{V}_{\mathrm{G} \text {-ref }}$ respectively. The reference signal for VSC is determined by converting $\mathrm{d}$ - and q-axis voltages, which are determined by the differences between reference $d-q$ axes currents and their detected values. Parameters of the PI controllers are determined by trial and error method. The PWM signal is generated for IGBT switching by comparing reference signals, which is converted to 3-phase sinusoidal wave with the triangular carrier signal. The frequency of the triangular carrier signal is chosen $450 \mathrm{~Hz}$. The DC voltage across the capacitor is 2000 Volt, which is kept constant throughout by the 6-pulse PWM converter.

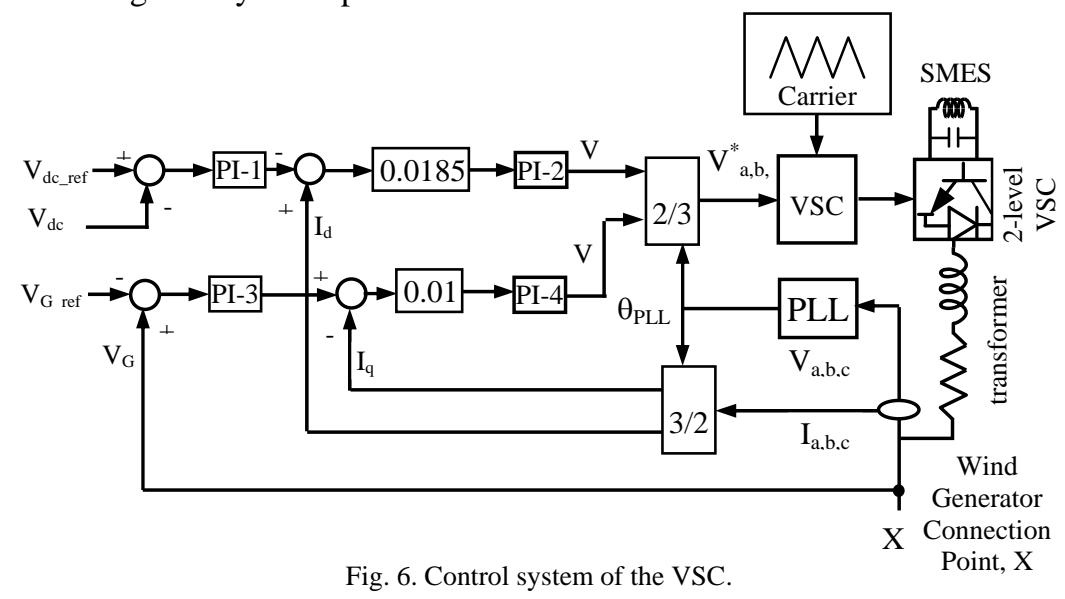

\subsection{Two-quadrant DC-DC chopper}

The superconducting coil is charged or discharged by adjusting the average (i.e., DC) voltage across the coil to be positive or negative values by means of the DC-DC chopper duty cycle, D. When the duty cycle is larger than 0.5 or less than 0.5 , the coil is either charging or discharging respectively. The control concept of coil energy charging and discharging is available in [18]. The DC-DC chopper is controlled to supply positive (IGBT is turned on) or negative (IGBT is turned off) voltage $\mathrm{V}_{\mathrm{sm}}$ to SMES coil and then the stored energy can be charged or discharged. When the unit is on standby, the coil current is kept constant, independent of the storage level, by adjusting the chopper duty cycle to $50 \%$, resulting in the net voltage across the superconducting winding to be zero. In order to generate the gate signals for the IGBT's of the chopper, the PWM reference signal is compared with the saw tooth carrier signal as in [18]. The frequency of the saw tooth carrier signal for the chopper is chosen $100 \mathrm{~Hz}$.

\section{Simulation Results and Performances}

Simulations are performed by using PSCAD/EMTDC [23]. In the transient stability analysis, the wind speed is kept constant at the rated speed $(11.8 \mathrm{~m} / \mathrm{s})$, assuming that the wind speed doesn't change dramatically within this small time duration. Two cases are considered to show the effectiveness of the proposed control system for transient stability enhancement. 


\section{Case-I: Both symmetrical (3LG) and unsymmetrical faults (2LG \& 1LG) are considered at point $F$ and no SMES unit is connected in the model system.}

For this case it is considered that fault occurs at $1.1 \mathrm{sec}$. The circuit breakers (CB) on the faulted line are disconnected at $1.2 \mathrm{sec}$ and the line is reinserted again by closing the $\mathrm{CB}$ at $2 \mathrm{sec}$. The time step and simulation time have been chosen as $0.00001 \mathrm{sec}$ and $5 \mathrm{sec}$ respectively. Responses of SG and IG are shown in Fig. 7(i) through Fig. 7(iii) and Fig. 8(i) through Fig. 8(iii), respectively. It is seen from the figures that the system have heavy fluctuation at the time of fault but during $1 \mathrm{LG}$ fault system becomes stable more rapidly than the case of 2LG fault. And 3LG fault have more impact on the overall system performance.

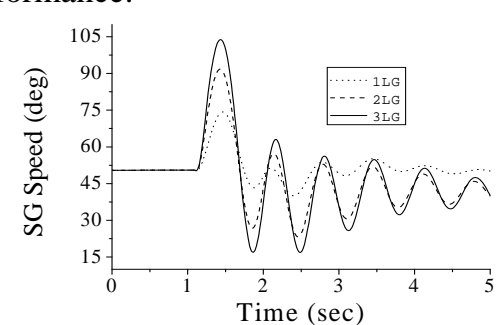

Fig. 7(i). Responses of synchronous generator speed [Case I].

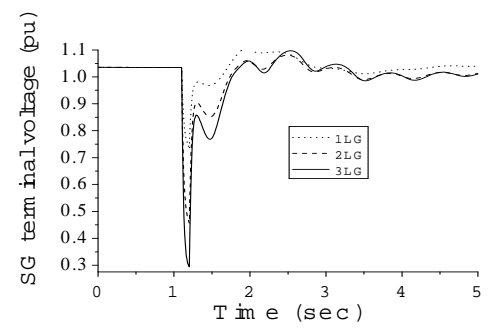

Fig. 7(ii). Responses of SG terminal voltage [Case I].

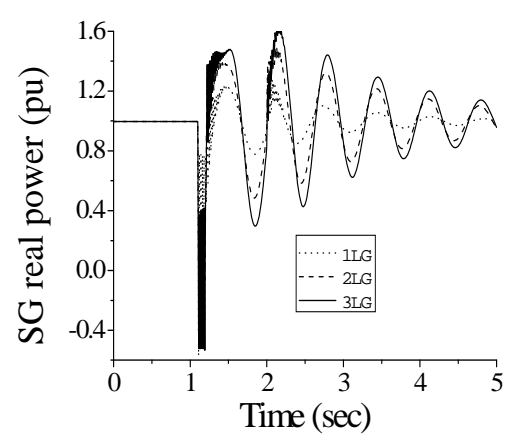

Fig. 7(iii).Responses of SG real power [Case I].

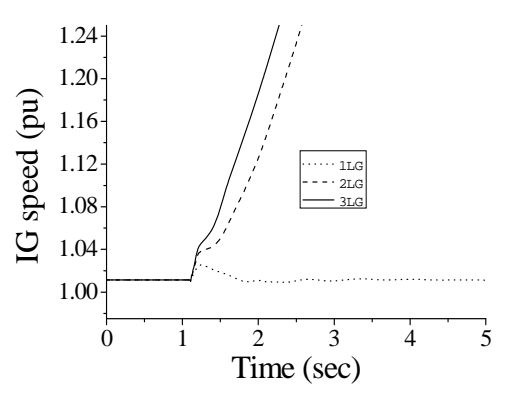

Fig. 8(i). Responses of IG speed [Case I].

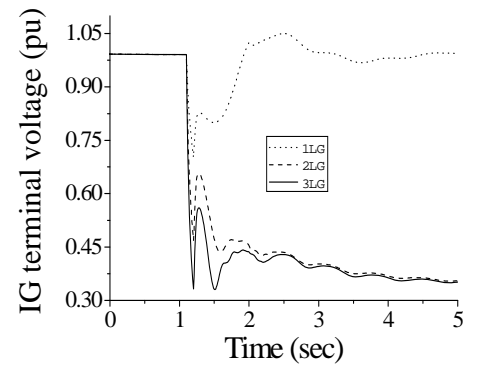

Fig. 8(ii). Responses of IG terminal voltage [Case I].

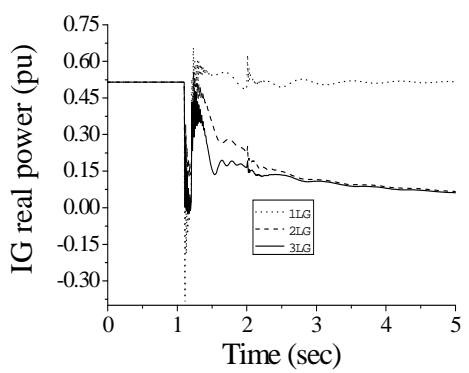

Fig. 8(iii). Responses of IG real power [Case I]. 


\section{Case-II: An unsymmetrical two-lines-to-ground fault (2LG) occurs at point $F$ near the synchronous generator at line \#2 in Fig.1 and SMES unit is connected.}

Figs. 9-14 show the simulation results for Case-II. Fig. 9 shows the responses of IG rotor speed. It is seen that because of the use of the proposed SMES, IG becomes stable quickly. Fig. 10 shows the responses of IG real power. In this case also it is seen that the proposed SMES can maintain the IG real power at rated level. Fig. 11 shows the responses of IG terminal voltage. It is seen that the IG terminal voltage returns back to its original value quickly due to the use of SMES. Fig. 12 shows the responses of SG load angle. It is clear that the synchronous generator is transiently more stable when the SMES is used. This fact also indicates that the proposed SMES unit can make the entire power system stable well. Figs. 13-14 show the responses of the real and reactive power of the SMES.

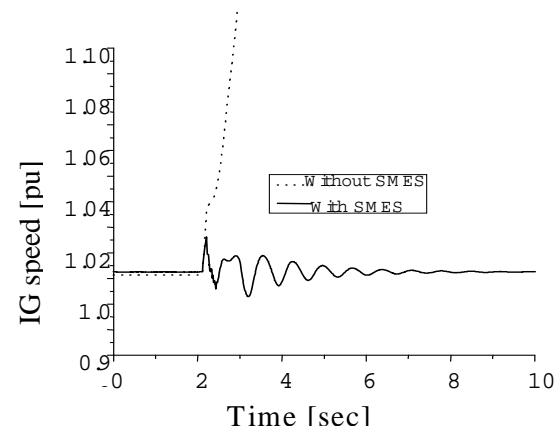

Fig. 9. Response of IG rotor speed [Case II].

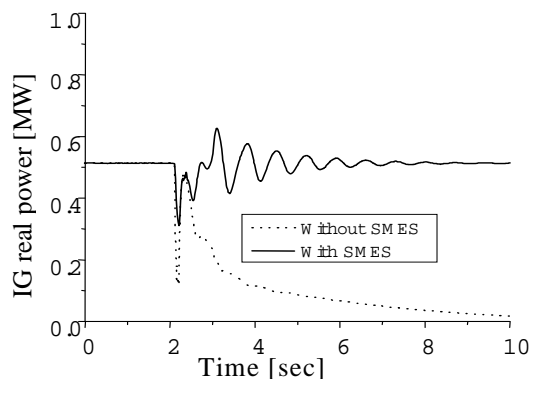

Fig. 10. Response of IG real power [Case II].

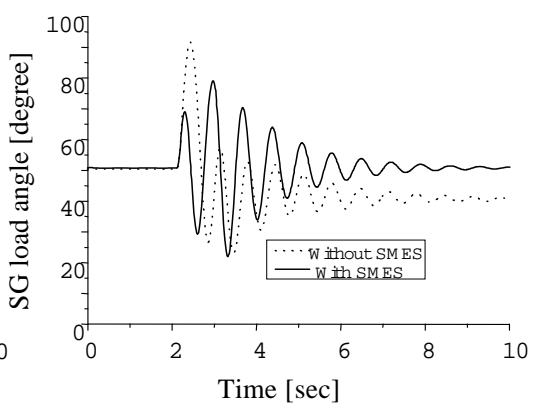

Fig. 12. Response of SG load angle
[Case II].
Fig. 11. Response of IG terminal voltage [Case II]. 


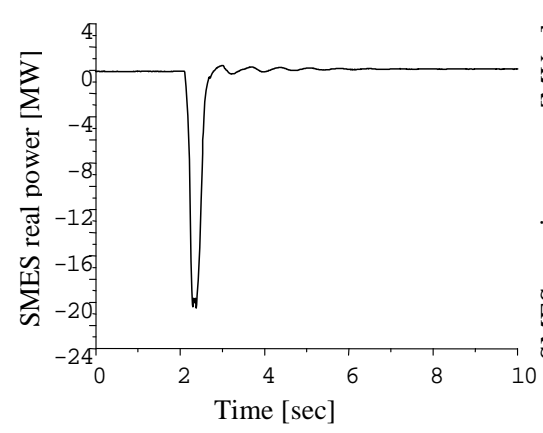

Fig. 13. Response of SMES real power [Case II].

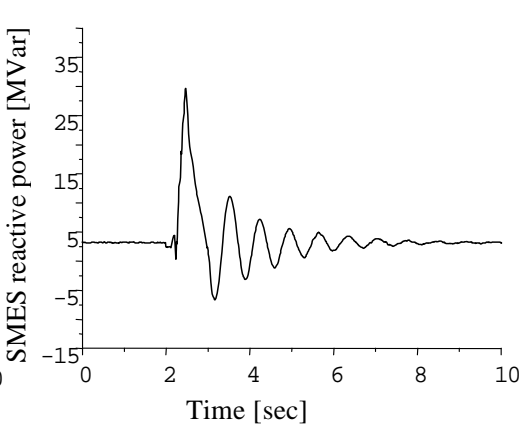

Fig. 14. Response of SMES reactive power [Case II].

\section{Conclusions}

This paper presents the detailed study about the transient stability of fixed speed wind turbine driving IG when a network disturbance occurs in the power system. Both symmetrical and unsymmetrical faults are considered as network disturbances. It is found that 3LG fault occurred near the generator is more severe than other type of fault. It is also seen that IG goes out of step for 2LG and 3LG faults without SMES, causing the heavy impact on IG for overall performance. So transient stability enhancement using the proposed controlled SMES is analyzed and it is seen that the SMES unit with the proposed controller can improve the dynamic performance of wind generator significantly. As a whole, it can be concluded that the proposed SMES strategy provides a very simple and effective means for stability enhancement of electric power system including wind generator.

\section{References}

1. P. Ledesma and J. Usaola, IEEE Transaction on Energy Conversion 20 (2), 388 (2005). doi:10.1109/TEC.2005.845523

2. P. La Seta and P. Schegner, Comparison of Stabilizing Methods for Doubly-fed Induction Generators for Wind Turbines, Int. Conf. Future Power System (Conference CDROM, 2005).

3. T. Sun, Z. Chen, and F. Blaabjerg, Wind energy 8 (3), 345 (2005). doi:10.1002/we.164

4. M. S. Morsey, H. H. Amer, M. A. Badr, and A. M. El-Serafi, IEEE Transaction on Power Apparatus and Systems 102 (4), 852 (1983). doi:10.1109/TPAS.1983.317949

5. J. Tamura, T. Yamazaki, M. Ueno, Y. Matsumura, and S. Kimoto, Transient Stability Simulation of Power System Including Wind Generator by PSCAD/EMTDC, IEEE Porto Power Tech. Proceedings, 4, EMT-108(2001).

6. Hulle FV., Large-Scale Integration of Wind Energy in the European Power Supply Analysis, issue and recommendations, EWEA Technical Report (2005). 
7. S. M. Muyeen, S. Shishido, Mohd. Hasan Ali, R. Takahashi, T. Murata, and J. Tamura, Wind Energy 11(4), 335(2008). doi:10.1002/we.265

8. E. S. Abdin and W. Xu, IEEE Transaction on Energy Conversion 15 (1), 91(2000). doi:10.1109/60.849122

9. Z. S.-Saoud, M. L. Lisboa, J. B. Ekanayake, N. Jenkins, and G. Strbac, Application of STATCOMs to Wind Farms, IEE Proc.- Generation, Transmission and Distribution, 145 (5), 511(1998). doi:10.1049/ip-gtd:19982178

10. R. Cardenas, R. Pena, G. Asher, and J. Clare, IEEE Transaction on Energy Conversion 19 (1), 206 (2004). doi:10.1109/TEC.2003.816605

11. T. Kinjo, T. Senjyu, N. Urasaki, and H. Fujita, IEEE Transaction on Energy Conversion 21 (1), 221 (2006). doi:10.1109/TEC.2005.853752

12. R. S. Bhatia, S. P. Jain, D. K. Jain, and B. Singh, Battery Energy Storage System for Power Conditioning of Renewable Energy Sources, Int. Conf. on Power Electronics and Drive Systems (Conference CDROM, 2005).

13. H. J. Boenig and J. F. Hauer, IEEE Transaction on Power Apparatus and Systems 104 (2), 302 (1985). doi:10.1109/TPAS.1985.319044

14. Y. Mitani, K. Tsuji, and Y. Murakami, IEEE Transaction on Power System 3, 1418 (1988).

15. S. Banerjee, J. K. Chatterjee, and S. C. Tripathy, IEEE Trans. on Energy Conversion 5, 46 (1990). doi:10.1109/60.50811

16. M. H. Ali, T. Murata, and J. Tamura, IEEE Transaction on Control Systems Technology 15 (1), 144 (2007). doi:10.1109/TCST.2006.883342

17. IEEE Task Force on Benchmark Models for Digital Simulation of FACTS and Custom-Power Controllers, T\&D Committee, IEEE Trans. Power Delivery 21 (2), 699 (2006). doi:10.1109/TPWRD.2005.864075

18. M. R. I. Sheikh, S. M. Muyeen, Rion Takahashi, Toshiaki Murata, and Junji Tamura, Transient Stability Enhancement of Wind Generator Using Superconducting Magnetic Energy Storage Unit, Int. Conf. of Electrical Machine, (Conference CDROM, 2008).

19. S. M. Muyeen, R. Takahashi, T. Murata, and J. Tamura, Transient Stability Enhancement of Wind Generator by Online Logical Pitch Controller with the consideration of Initial Condition Settings, Proceeding of the IPEC (2005-4).

20. S. M. Muyeen, M. H. Ali, R. Takahashi, T. Murata, and J. Tamura, IEEJ Transactions on Power and Energy 126-B, 742 (2006). doi:10.1541/ieejpes.126.742

21. S. Heier, Grid Integration of Wind Energy Conversion System, John Wiley \& Sons Ltd., (1998)

22. P. M. Anderson and A. Bose, IEEE Transaction on Power Apparatus System 102 (12), 3791 (1983). doi:10.1109/TPAS.1983.317873

23. PSCAD/EMTDC Manual, Manitoba HVDC Research Center (1994). 